\title{
Diagnóstico da região Centro-Oeste na rede de informação em comunicação em língua portuguesa - Portcom/Intercom
}

\author{
Maria Auxiliadora Andrade de Echegaray*
}

\section{Resumo}

Apresenta o status quo organizacional das Bibliotecas públicas e privadas da região Centro-Oeste do Brasil, que atuam na área de Comunicação. Traz dados estatísticos sobre automação, serviços e produtos, tipos de documentos, acervo, entre outras informações necessárias à elaboração de um diagnóstico setorial que sirva de subsídio para a implantação da Rede de Informações em Comunicação.

Palavras-chave: Portcom/Intercom, bibliotecas universitárias - diagnóstico.

\section{Introdução}

A Rede de Informações em Comunicação em Língua PortuguesaPORTCOM tem como objetivo precípuo a coleta, a organização e a disseminação da produção técnico-científica e artística de professores, alunos e técnicos que integram os Programas de Pós-Graduação (lato e stricto sensu) das Universidades e de outros profissionais, nos diversos veículos ou canais de comunicação científica.

Este trabalho enfoca a região Centro-Oeste, incluindo Goiás, Distrito Federal, Mato Grosso, Mato Grosso do Sul, e uma cidade da região Norte, Palmas (Estado do Tocantins).

Foram selecionadas 10 Instituições de Ensino Superior-IES, assim distribuídas: Brasília - 04, Mato Grosso - 01, Mato Grosso do Sul 03, Goiás - 01, Tocantins - 01 .

* Bibliotecária, Mestre em História das Sociedades Agrárias, Diretora da Faculdade de Comunicação e Biblioteconomia/UFG, Membro do Comitê Assessor da PORTCOM/Representante da Região Centro-Oeste.

Comun. Inf., v. 3, n. 1, p. 101-115, jan./jun. 2000 
102

Para levantamento dos dados foi utilizado um questionário elaborado pelo Grupo de Trabalho do PORTCOM/INTERCOM e enviado pelos representantes regionais para todas as Bibliotecas pertencentes a Instituições Públicas e Privadas.

O retorno dos questionários foi surpreendente: $100 \%$ foram respondidos. A pesquisa revelou que $50 \%$ das bibliotecas pertencem à rede pública e $50 \%$ à rede privada (ver Tabela 1)

Tabela 1 - IES/Comunicação-Região Centro-Oeste (DF, GO,MT, MS E TO)

\begin{tabular}{|lcc|}
\hline INSTITUIÇÕES & PÚBLICAS & PRIVADAS \\
\hline UFG & $\mathrm{X}$ & \\
UFMT & $\mathrm{X}$ & \\
UFMS & $\mathrm{X}$ & \\
UnB & $\mathrm{X}$ & \\
UNITINS & $\mathrm{X}$ & $\mathrm{X}$ \\
CESUP & & $\mathrm{X}$ \\
UNIBOSCO & & $\mathrm{X}$ \\
UCB & & $\mathrm{X}$ \\
UniCEUB & & $\mathrm{X}$ \\
UNIP & & \\
\hline
\end{tabular}

Com relação ao modelo administrativo (tipos de bibliotecas), observa-se que $80 \%$ são bibliotecas centrais, $10 \%$ bibliotecas centrais/setoriais e $10 \%$ sistemas - compostos de 03 bibliotecas (ver Figura 1).

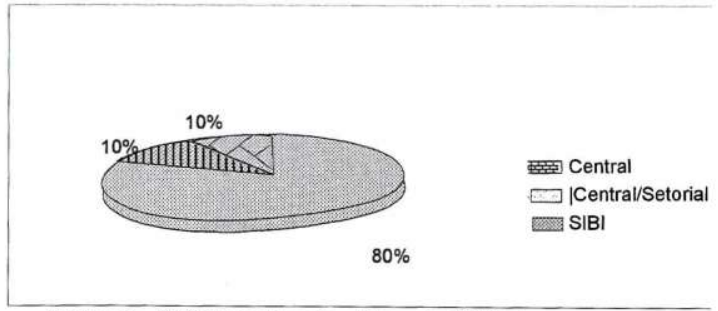

Figura 1 - IES/Comunicação - Tipos de Bibliotecas

Comun. Inf., v. 3, n. 1, p. 101-115, jan./jun. 2000 


\section{Situação atual das bibliotecas}

A Figura 2 identifica a cobertura temática das coleções em relação às necessidades informacionais dos Cursos de Comunicação oferecidos na Região. Jornalismo e Publicidade \& Propaganda atingiram o maior índice de representatividade - $80 \%$; Produção Editorial e Relações Publicas - 70\%; Radialismo - 60\%; Cinema - 30\%. Já outras áreas do conhecimento, incluindo Marketing, atingiram $20 \%$.

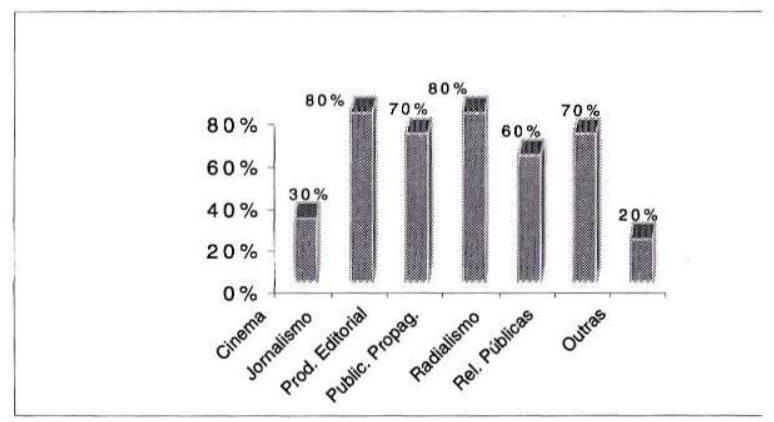

Figura 2 - IES/Comunicação - Cobertura Temática

A Figura 3 demonstra os níveis de centralização dos serviços das bibliotecas centrais. O Processamento Técnico atingiu o mais elevado índice (90\%), seguido da Aquisição, Gerência e Seleção (70\%).

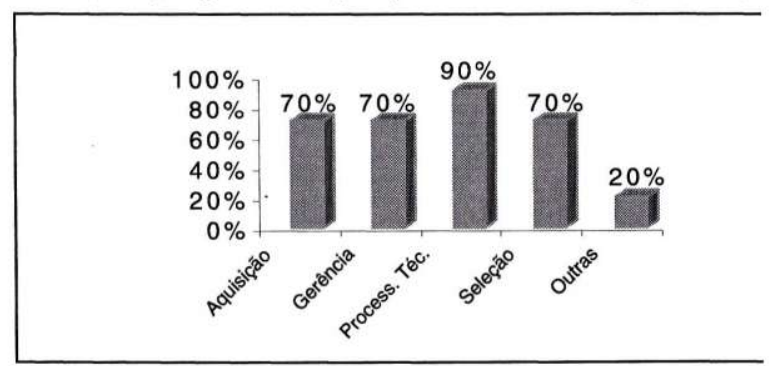

Figura 3 - IES/Comunicação - Atividades Centralizadas

Comun. Inf., v. 3, n. 1, p. 101-115, jan./jun. 2000 


\section{4}

Observa-se que, das 10 bibliotecas que constituíram a amostra, $70 \%$ estão automatizadas e $30 \%$ parcialmente automatizadas, deduzindo-se que as instituições estão adotando novas tecnologias e softwares para atender às demandas informacionais.

Nota-se na Figura 4 que o Microisis e o Thesaurus são os softwares mais utilizados pelas bibliotecas (30\%), considerando que $20 \%$ não responderam a este item.

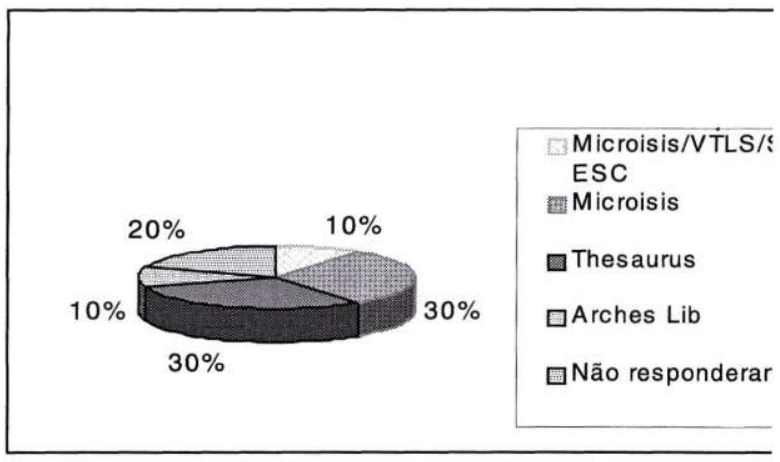

Figura 4 - IES/Comunicação - Softwares Utilizados

Quanto à utilização de instrumentos para processamento técnico, observa-se na Figura 5 que todas as 10 bibliotecas da amostra usam o AACR2. Como segundo instrumento, 7 usam a CDU.

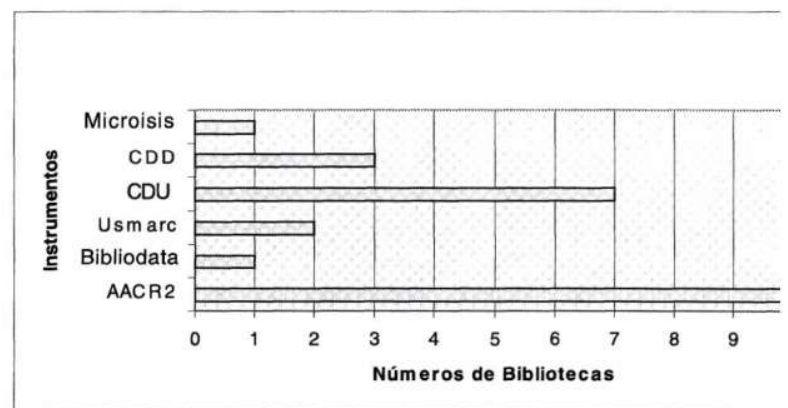

Figura 5-IES/Comunicação-Instrumentos para Processamento Técnico

Comun. Inf., v. 3, n. 1, p. 101-115, jan./jun. 2000 
Verifica-se na Figura 6 que $80 \%$ das bibliotecas utilizam o terminal para ter acesso ao catálogo geral. A forma manual é utilizada por $40 \%$, o mesmo acontecendo com a Internet. Já a Intranet atingiu o índice de $30 \%$.

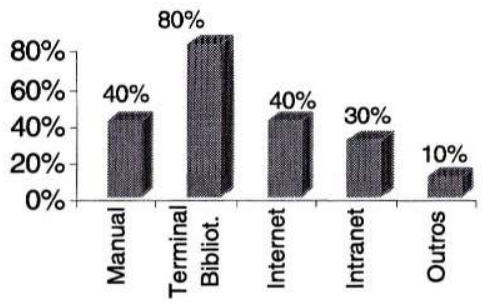

Figura 6 - IES/Comunicação - Acesso ao Catálogo Geral

A Figura 7 demonstra que todas as bibliotecas possuem livros, mas que $90 \%$ possuem também teses/dissertações e $50 \%$ títulos de periódicos, o que demonstra ainda o predomínio do livro.

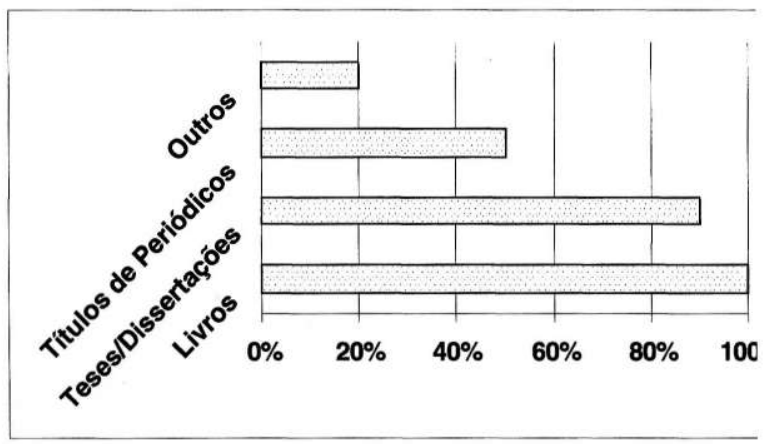

Figura 7 - IES/Comunicação - Conteúdo do Catálogo

Comun. Inf., v. 3, n. 1, p. 101-115, jan./jun. 2000 
106

O Empréstimo está automatizado em $90 \%$ das bibliotecas, o que pode ser observado na Figura 8. A Aquisição, a Seleção e outros serviços atingiram o índice de $40 \%$.

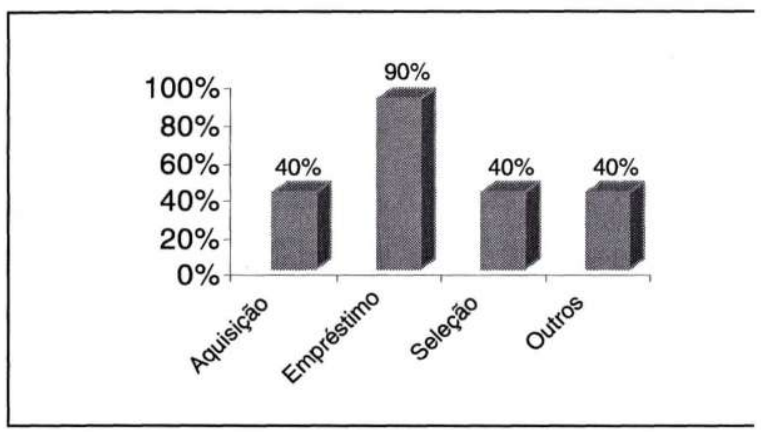

Figura 8 - IES - Comunicação - Serviços Automatizados

A figura 9 demonstra que o COMUT é a rede mais utilizada pelas bibliotecas (90\%), o CCN vem em segundo lugar - $60 \%$.

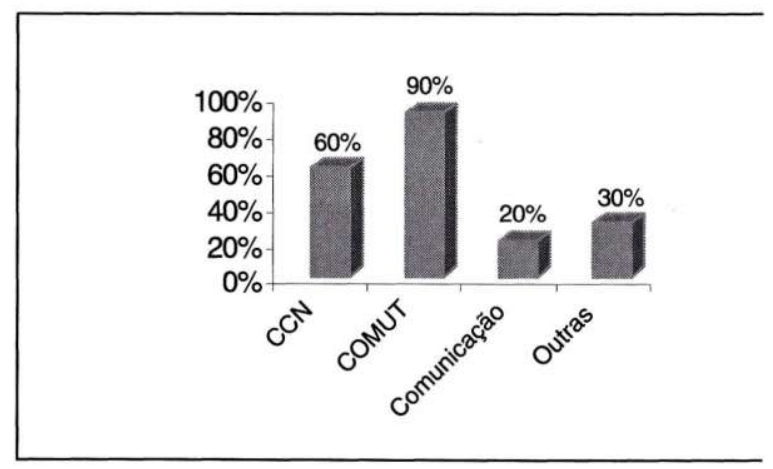

Figura 9 - IES/Comunicação - Redes

Comun. Inf., v. 3, n. 1, p. 101-115, jan./jun. 2000 
$\mathrm{Na}$ área específica de Comunicação, conforme mostra a Figura 10 , há uma equivalência no acesso ao catálogo entre o terminal da biblioteca e a Internet (50\%), o que demonstra que o acesso manual é menor (30\%).

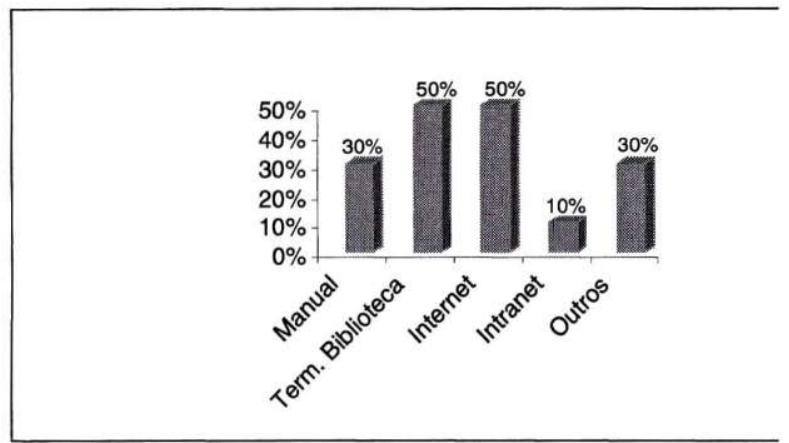

Figura 10 - IES/Comunicação - Acesso ao Catálogo/Comunicação

Observa-se também que na área de Comunicação o software mais utilizadoé o Thesaurus (40\%), considerando que $40 \%$ não responderam (ver Figura 11).

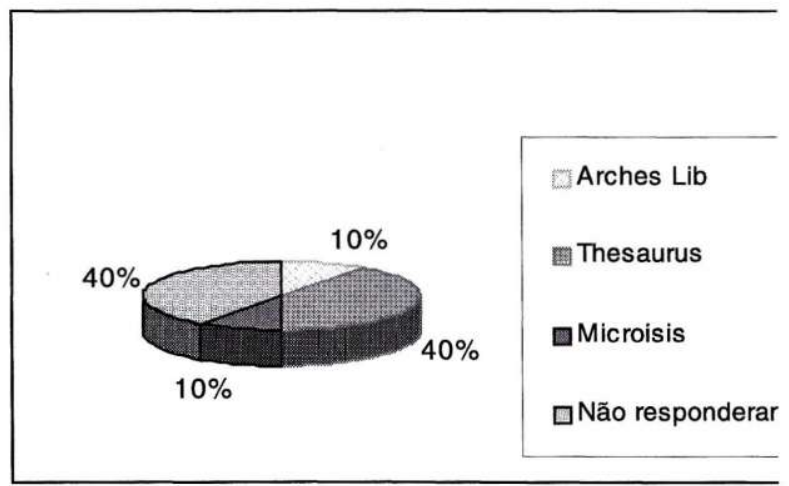

Figura 11 - IES/Comunicação - Softwares utilizados/Comunicação

Comun. Inf., v. 3, n. 1, p. 101-115, jan./jun. 2000 


\section{8}

Vale registrar que apenas $20 \%$ das bibliotecas da amostra indicaram o número de registros, que perfaz o total de 2.609.

Para a coleção de Comunicação, nos instrumentos utilizados para Processamento Técnico, prevalecem a Linguagem CDU (60\%) e CDD (10\%). Na Catalogação prevaleceu o AACR2 (50\%) e no Formato, oUsmarc (20\%), considerando que $70 \%$ não responderam (ver Figura 12,13 e 14 , respectivamente).

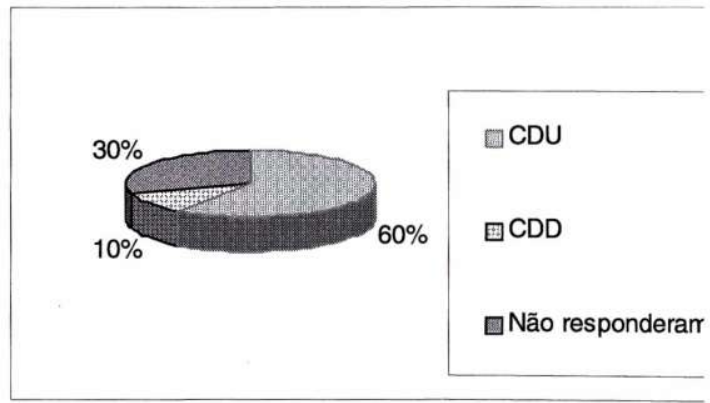

Figura 12 - IES/Comunicação - Linguagem/Comunicação

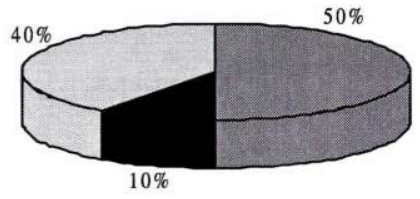

$\square \mathrm{ACR} 2$

$\square$ Outro

口Não Responde।

Figura 13 - IES/Comunicação - Catalogação/Comunicação

Comun. Inf., v. 3, n. 1, p. 101-115, jan./jun. 2000 


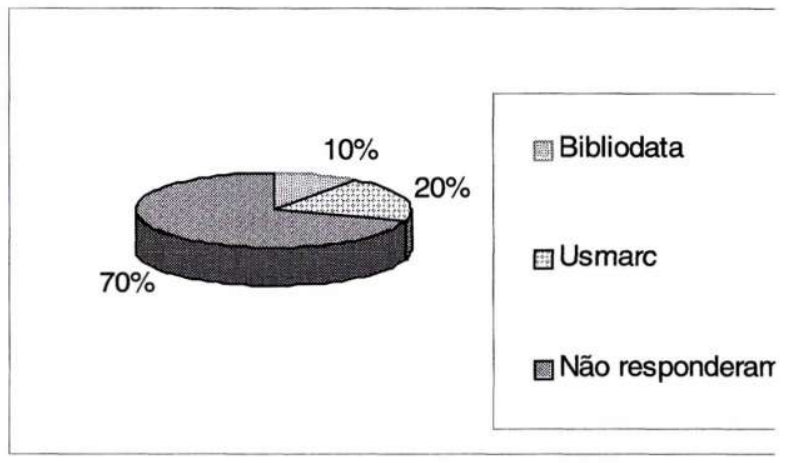

Figura 14 - IES/Comunicação - Formato/Comunicação

No que se refere ao conteúdo dos catálogos elaborados pelas bibliotecas na área de Comunicação, 80\% não responderam. Os itens livros/periódicos e livros atingiram um percentual de $10 \%$ cada um (ver Figura 15).

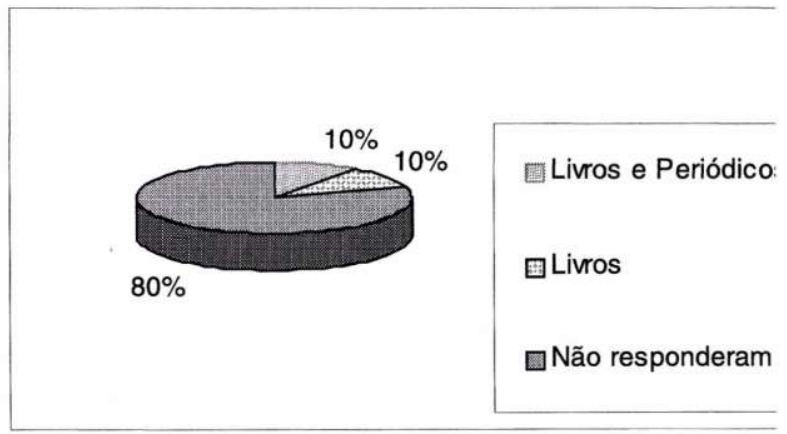

Figura 15 - IES/Comunicação - Conteúdo dos Catálogos/Comunicação

Já as Bases de Dados Bibliográficas são constituídas apenas de vídeos e teses (10\%), já que $90 \%$ das bibliotecas não responderam (ver Figura 16).

Comun. Inf., v. 3, n. 1, p. 101-115, jan./jun. 2000 


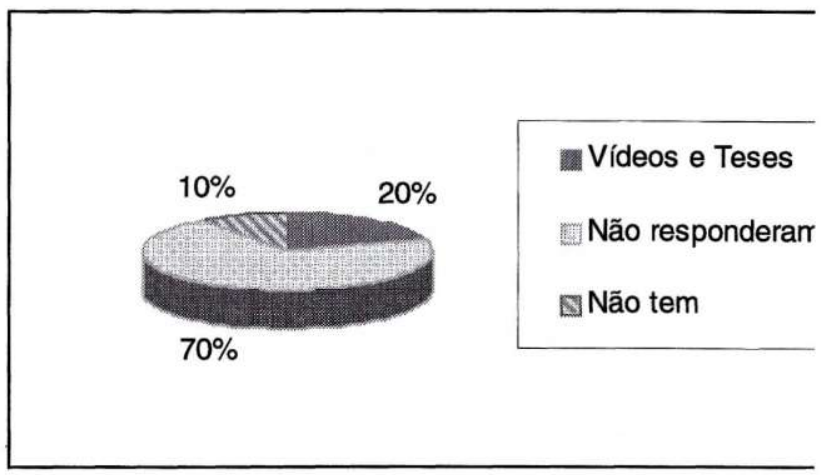

Figura 16 - IES/Comunicação - Produção - Conteúdo das Bases de Dados/Comunicação

Com relação à produção de Bases de Dados em temas da Comunicação, observa-se que as bibliotecas pouco produzem. Base Bibliográfica: $30 \%$; Texto Completo: nenhum, ressaltando-se que $70 \%$ não responderam.

No que diz respeito ao acesso à Base de Dados, foram mencionadas com maior destaque apenas a Internet (30\%) e o terminal da biblioteca (20\%). Não foram demonstradas no gráfico as respostas negativas ou em branco. Ver figura 17.

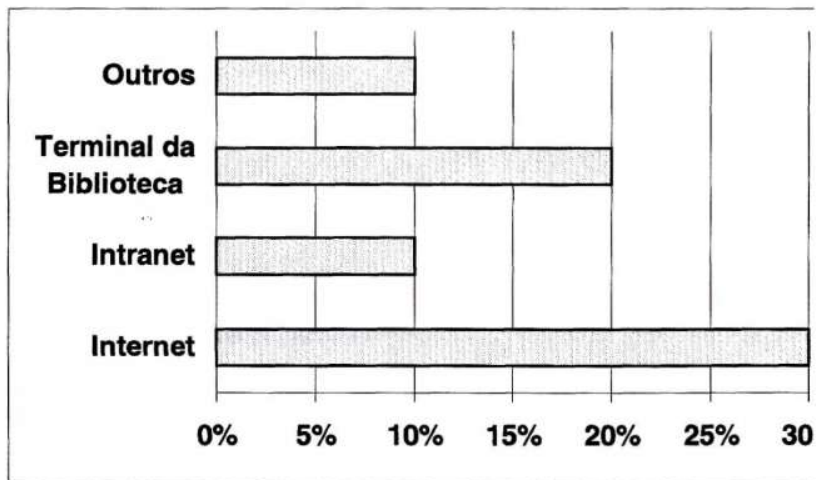

Figura 17 - IES/Comunicação - Produção -Acesso a Bases de Dados/Comunicação

Comun. Inf., v. 3, n. 1, p. 101-115, jan./jun. 2000 
Dos softwares mencionados pelas bibliotecas destaca-se o Thesaurus - 20\%. O Arches Lib e o Microisis atingiram, cada um, o índice de 10\%. Ver Figura 18.

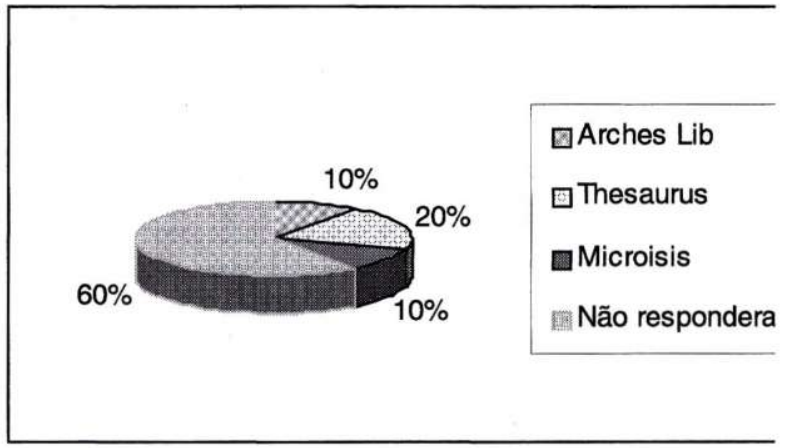

Figura 18 - IES/Comunicação - Softwares Utilizados

É importante enfatizar que apenas uma biblioteca informou o número de registros em temas da Comunicação: 1.229.

A Figura 19 mostra que $50 \%$ das bibliotecas não indexam periódicos. O índice de indexação é de apenas $20 \%$, com a ressalva de que $30 \%$ não responderam a este item.

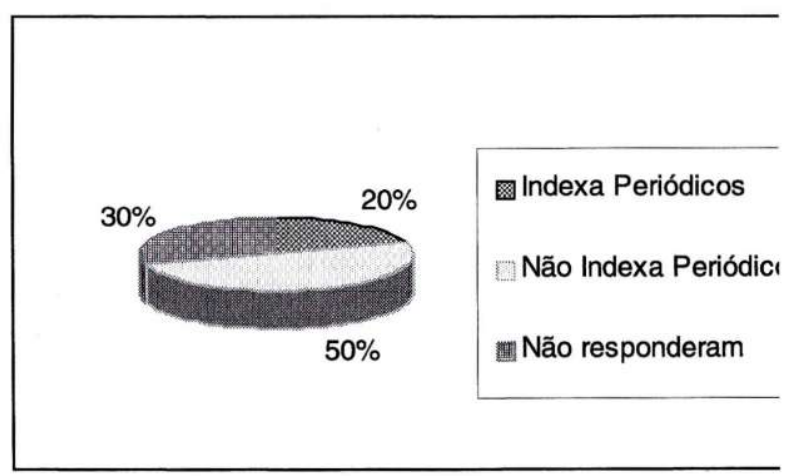

Figura 19 - IES/Comunicação - Indexação de Periódicos

Comun. Inf., v. 3, n. 1, p. 101-115, jan./jun. 2000 
As bibliotecas da amostra não indicaram os instrumentos usados na indexação, pelo menos entre os que lhes foram oferecidos como opção. Em "outros instrumentos" foi mencionado o descritor livre, mas apenas por uma biblioteca.

Dos Serviços e Produtos On line oferecidos, verifica-se que a Base! Suporte (Cd-rom / Internet) alcançou o maior índice (70\%), conforme demonstra a Figura 20.

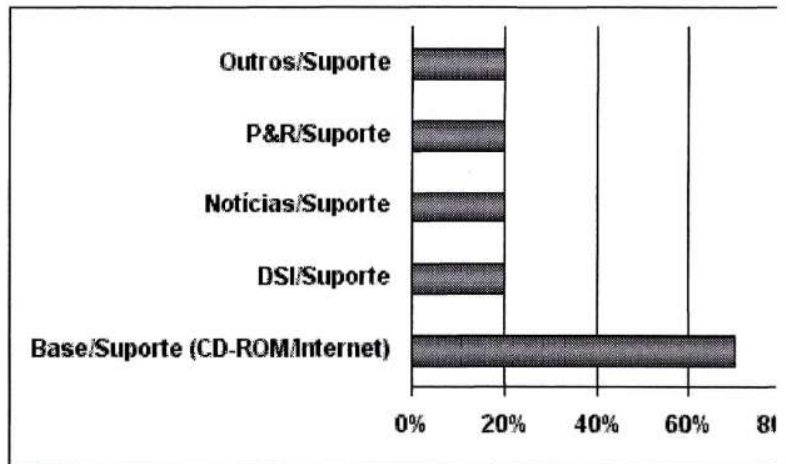

Figura 20 - IES/Comunicação - Serviços e Produtos On line

A pesquisa indica que $40 \%$ das bibliotecas elaboram publicações periódicas impressas, totalizando 8 publicações. Contudo, nenhuma publicação eletrônica foi mencionada.

Das bibliotecas que responderam ao tópico "filmes/áudio", apenas $30 \%$ informaram que possuem 238 itens na área de Comunicação e, em outras áreas, em torno de 8.015.

Com referência ao acervo de livros, que possui o maior peso, as bibliotecas têm 11.236 exemplares da área de Comunicação e 412.391 em outras áreas. $\mathrm{O}$ total geral chega a 431.463. Vale enfatizar que o índice de respostas chegou a $60 \%$ na área de Comunicação e 50\% em outras áreas.

O acervo de teses e dissertações é de 2.049 na área de Comunicação e 652.711 em outras áreas. O total geral atinge 654.070 exemplares. $O$ índice de respostas foi o seguinte: $40 \%$ (área de Comunicação), 50\% (outras áreas).

Comun. Inf., v. 3, n. 1, p. 101-115, jan./jun. 2000 
Os periódicos internacionais somam, na área de Comunicação, 231 títulos, considerando um índice de respostas de $50 \%$. Em outras áreas atinge a soma de 6.785 títulos, com um retorno de $40 \%$ de respostas. No que se refere aos periódicos nacionais, as bibliotecas possuem 412 títulos na área de Comunicação e 3.734 em outras áreas. As respostas atingiram o porcentual de $50 \%$.

No que diz respeito ao TCC, é importante dizer que foi inexpressiva a sua presença no acervo das bibliotecas. Na área de Comunicação foram mencionados apenas 26 trabalhos.

A Tabela 2, que trata do Quadro de Pessoal das Bibliotecas, demonstra que quantitativamente a categoria privilegiada é a de Técnicos Administrativos de nível médio, seguida pela de Bibliotecários .

Tabela 2 - Quadro de pessoal das bibliotecas

\begin{tabular}{|lc|}
\hline PESSOAL & NÚMERO \\
\hline Bibliotecários & 80 \\
Bolsistas & 55 \\
TA Superior & 52 \\
TA Médio & 165 \\
Outros & 22 \\
\hline
\end{tabular}

A pesquisa não apontou a produção técnico-científica das Instituições, o que revela a falta de controle dessa produção por parte das bibliotecas. É dispensável falar sobre a importância da produção técnico-científica das Universidades, considerando a grande massa crítica que possuem.

Já com relação a Projetos, duas bibliotecas apenas disseram estar implementando-os: uma na área de Hemeroteca, e outra no campo da duplicação de documentos eletrônicos.

\section{Considerações finais}

O esforço conjunto dos diversos segmentos da comunidade acadêmica é que irá garantir o sucesso do Grupo de Trabalho do PORTCOM/INTERCOM.

A Região Centro-Oeste foi um exemplo de adesão ao trabalho do Grupo; os questionários foram todos respondidos, embora tenham sido detectadas algumas lacunas - questões em branco.

Comun. Inf., v. 3, n. 1, p. 101-115, jan./jun. 2000 


\section{4}

Constatou-se um certo equilíbrio entre os investimentos no ensino superior na região, uma vez que $50 \%$ das bibliotecas da amostra pertencem à rede pública $\mathrm{e} 50 \%$ à rede privada. Todavia, essa constatação não deve levar à crença de que, de uma maneira geral, o Governo Federal investe com eqüidade nas duas modalidades de ensino.

Dos cursos de Comunicação Social, as habilitações Publicidade e Propaganda, Jornalismo, Relações Públicas e Produção Editorial são as que apresentam uma melhor cobertura temática.

A adoção de novas tecnologias, identificada na pesquisa, promete uma relativa facilidade na implantação da Rede de Informação em Comunicação.

Não se pode ignorar que, embora $80 \%$ das bibliotecas tenham acesso ao catálogo geral através do terminal, $40 \%$ ainda o fazem de forma manual, o que denota a persistência de serviços artesanais. A presença desses serviços e o alto índice de técnicos administrativos de nível médio sugerem a necessidade de programas de treinamento ou de educação continuada.

No que se refere à área de Comunicação, observam-se algumas restrições quanto ao tratamento e o acesso às informações, serviços e produtos.

A hegemonia do livro persiste, em detrimento de outros documentos, e o porcentual referente a periódicos ainda é inexpressivo.

É importante ressaltar que a Internet já é uma realidade, a grande maioria das bibliotecas já a utiliza, embora as Bases de Dados ainda não atendam satisfatoriamente às demandas dos usuários, principalmente na área de Comunicação.

O diagnóstico infere que algumas medidas de emergência devem ser adotadas no sentido de preparar as bibliotecas para a implantação da Rede de Informações em Comunicação, principalmente a disseminação de novas tecnologias da informação. São elas que irão permitir o acesso, em tempo real, às informações relevantes na área de Comunicação, uma área dinâmica por excelência, um dos pilares da Sociedade da Informação e, mais propriamente, do Conhecimento.

\section{Abstract}

It presents the status quo of organization of the public and private Libraries of the area Center-west of Brazil, that act in the area of Communication. It brings data statisticians on automation, services and products, types of documents,

Comun. Inf., v. 3, n. 1, p. 101-115, jan./jun. 2000 
collection, among other necessary information to the elaboration of a sectorial diagnosis that serves as subsidy for the implantation of the Net of Information in Communications.

Key words: PORTCOM/INTERCOM, academical libraries - diagnosis.

\section{Referências}

CAVALCANTI, Ilce G. Milet. Padrões de citação em Comunicação: análise das dissertações apresentadas à ECO/UFRJ. Orientadora: Gilda Maria Braga.Rio de Janeiro: UFRJ/ECO-CBOq/IBICT, 1989. 135p. 